\title{
I DO NOT OWN SNOW WHITE
}

¿Qué puede pensar alguien que entra a la Tate y ve: Blancanieves

no me pertenece?... Blancanieves

le pertenece a cualquiera que haya visto

Blancanieves;

por supuesto. Tienes que jugar con

la escultura

para ser parte de ella.

Si alguien ve Blancanieves

no me pertenece,

$\mathrm{y}$ entiende,

quizá pueda dejar de

jugar

con ella...

Es acerca de la circulación

de las historias.

Es acerca de cómo

nos contamos historias

unos a otros.

Y el modo en que esto puede resultar

muy fluido

o fluir muy poco... Por eso

hay puertas sueltas

moviéndose

en este cuarto; un umbral.

Decimos:

¿estás adentro de algo?

$\mathrm{O}$

¿estás afuera de algo?... 
Si el umbral se mueve, se mueven

las puertas.

Pero ya no hay

umbral. Ya no hay "adentro"

y

"afuera"...

(Transcripción / traducción de una entrevista con Pierre Huyghe)

\section{ABISINIA DESKTOP}

1

Un plano inclinado.
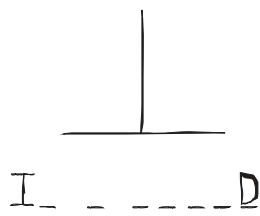

[Le dormeur du bois] $]$

Un spelling contest una soga un libro de texto.

El gis, el pizarrón.

Trazar verticalmente el horizonte simbólico@; traducir / acantilar las letras: el valle / el bosque; las dos balas / la soga; heroísmo C / deserción

(pero, ¿también el ejército francés ahorcaba a sus traidores?, y si sí, ¿de quién son los derechos?)

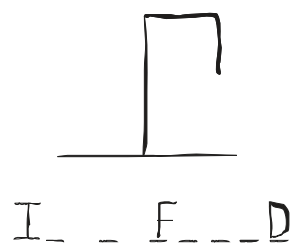

